\title{
Inhibition of Release of Arachidonic Acid by Monodansylcadaverine during Activation of Human Platelets by Collagen
}

\author{
Hwa Jin Park, Hiroshi Narita, Ken-ichi Tanaka,* \\ Takao MatsuURA* and Makoto Kito \\ Research Institute for Food Science, Kyoto University, \\ Uji, Kyoto 611, Japan \\ * Kyoto Red Cross Blood Center, Higashiyama-ku, Kyoto, \\ Kyoto 605, Japan
}

Received October 3, 1985

\begin{abstract}
Monodansylcadaverine $(250 \mu \mathrm{M})$, an inhibitor of transglutaminase, completely inhibited aggregation of human platelets induced by $2 \mu \mathrm{g} / \mathrm{ml}$ of collagen. Platelet responses necessary for aggregation (shape change, serotonin release, and phosphorylation of the 47,000-Da protein) were also inhibited by this reagent. However, incorporation of $\left[{ }^{3} \mathrm{H}\right]$ putrescine into platelet proteins was very low and independent of the stimulation by collagen. It seems unlikely, therefore, that the transglutaminase reaction participates in platelet aggregation. Monodansylcadaverine inhibited the formation of thromboxane $\mathrm{A}_{2}$ with a similar median inhibitory concentration (about $120 \mu \mathrm{M}$ ) for aggregation. When platelets prelabeled with $\left[{ }^{14} \mathrm{C}\right]$ arachidonic acid were stimulated by collagen, the radioactivities in thromboxane $\mathbf{B}_{2}$, hydroxyheptadecatrienoic acid, and hydroxyeicosatetraenoic acid increased. The increase was completely suppressed by the addition of monodansylcadaverine. Radioactivity in free arachidonic acid was very low throughout the experiments. From these results, it was concluded that monodansylcadaverine inhibited platelet aggregation by suppressing the release of arachidonic acid from phospholipids during platelet activation by collagen.
\end{abstract}

When platelets are stimulated by stimuli such as collagen, thrombin, or ADP, arachidonic acid is rapidly liberated from membrane phospholipids. The arachidonic acid liberated is subsequently metabolized to thromboxane $\mathrm{A}_{2}$, hydroxyheptadecatrienoic acid, and hydroxyeicosatetraenoic acid. It has been reported from this laboratory that thromboxane $A_{2}$ is central in collagen-induced aggregation of rat $^{1)}$ and human ${ }^{2}$ platelets.

Monodansylcadaverine is a monoamine inhibitor of receptor-mediated endocytosis that inhibits transglutaminase (R-glutaminyl-peptide: amine $\quad \gamma$-glutamyltransferase, EC.2.3.2.13). ${ }^{3,4)}$ Since the enzyme is present in platelets and able to polymerize platelet actin, myosin, and tropomyosin, ${ }^{5}$ 7) the possibility of participation of the enzyme in platelet aggregation was proposed. ${ }^{8,9)}$ Recently it was reported that monodansylcadaverine per- turbed phosphatidylcholine and phosphatidylinositol synthesis in rabbit neutrophils, ${ }^{10,11)}$ that several amines influenced various platelet responses, ${ }^{12)}$ and that thrombin induced the specific binding of transglutaminase to human platelets. $^{13)}$

In this paper, we examined the effects of monodansylcadaverine on platelet aggregation induced by collagen and found that monodansylcadaverine inhibited platelet aggregation by suppressing the release of arachidonic acid from phospholipid and that the transglutaminase reaction was not involved in this process.

\section{MATERIALS AND METHODS}

Materials. $\left[1-{ }^{14} \mathrm{C}\right]$ arachidonic acid $(40 \sim 60 \mathrm{mCi} / \mathrm{mmol})$, $\left[{ }^{3} \mathrm{H}\right]$ serotonin $(23 \mathrm{Ci} / \mathrm{mmol})$, thromboxane $\mathrm{B}_{2}$ radioimmunoassay kits, $\left[2,3-{ }^{3} \mathrm{H}(\mathrm{N})\right]$ putrescine dihydrochloride 
(21.4 Ci/mmol) and Aquasol were purchased from New England Nuclear, Boston. Carrier-free ${ }^{32} \mathrm{Pi}$ was purchased from the Japan Radioisotope Association. Silica Gel G plates (Merck, Darmstadt), NCS solubilizer (Amersham, Buckinghamshire), collagen from horses (HormonChemie, München), human plasma thrombin (Midorijuji), and monodansylcadaverine (Sigma, St. Louis) were purchased from the indicated sources. Other chemicals were of reagent grade.

Preparation of platelets. Blood was drawn from normal human volunteers using citrate-phosphate-dextrose as an anticoagulant. Platelet rich plasma was obtained by centrifugation at $1000 \times g$ for $5 \mathrm{~min}$. If necessary, mild centrifugation was repeated to remove red cells. Platelets were washed twice with a Tris-citrate-bicarbonate buffer, $\mathrm{pH}$ $6.5,{ }^{14)}$ containing $2 \mathrm{~mm}$ EDTA after centrifugation at $1500 \times g$ for $10 \mathrm{~min}$. Washed platelets were finally suspended in the Tris-citrate-bicarbonate buffer without EDTA to a final concentration of $10^{9}$ platelets $/ \mathrm{ml}$.

For $\left[{ }^{14} \mathrm{C}\right]$ arachidonic acid or ${ }^{32} \mathrm{Pi}$ labeling, 4-fold concentrated platelet-rich plasma $(20 \mathrm{ml})$ was incubated with $5 \mu \mathrm{Ci}$ of $\left[{ }^{14} \mathrm{C}\right]$ arachidonic acid at room temperature or $2 \mathrm{mCi}$ of ${ }^{32} \mathrm{Pi}$ at $37^{\circ} \mathrm{C}$ for $60 \mathrm{~min}$. Labeled platelets were then washed twice and suspended as described above. Before use, $\mathrm{CaCl}_{2}$ was added to a final concentration of $2 \mathrm{~mm}$.

Scanning electron microscopy. Washed platelets were preincubated with or without $250 \mu \mathrm{M}$ monodansylcadaverine for $3 \mathrm{~min}$, then stimulated by $2 \mu \mathrm{g} / \mathrm{ml}$ of collagen for $1 \mathrm{~min}$ in a aggregometer while stirring. Platelets were fixed with an equal volume of $2.5 \%$ glutaraldehyde and postfixed with $1 \% \mathrm{OsO}_{4}$, then filtered through a $0.2 \mu \mathrm{m}$ Nuclepore filter. After dehydration and coating with carbon and gold, platelets were examined in a Hitachi S-450 scanning electron, microscope at an accelerating voltage of $15 \mathrm{kV}$.

Lipid metabolism. Sample of the suspension of $\left[{ }^{14} \mathrm{C}\right]$ labeled platelets $(3 \sim 4 \mathrm{ml})$ were incubated with or without monodansylcadaverine for $3 \mathrm{~min}$ and then stimulated with $20 \mu \mathrm{g} / \mathrm{ml}$ of collagen for various intervals at $37^{\circ} \mathrm{C}$ while being gently stirred. Lipids were extracted as reported previously ${ }^{15}$ ) with the water phase adjusted to $\mathrm{pH} 3$ to extract arachidonic acid metabolites completely. The extracts were analyzed by TLC on Silica Gel G plates using the following separation system: upper phase of ethylacetate-isooctane-acetic acid-water $(90: 50: 20: 100) .{ }^{16)}$ The lipids were visualized by radioautography and counted by liquid scintillation in Aquasol-water-methanol (83:12:5).

Other analyses. Thromboxane $\mathrm{B}_{2}$ was measured with radioimmunoassay kits according to the instructions provided by the manufacturer. Platelets were aggregated as described previously. ${ }^{15)}$ Secretion of serotonin was mea- sured by the method of Costa and Murphy. ${ }^{17)}$ Protein phosphortylation was analyzed by the method of Laemmli. $^{18)}$

\section{RESULTS AND DISCUSSION}

\section{Inhibition of human platelet aggregation by monodansylcadaverine}

Monodansylcadaverine inhibited the aggregation of human platelet-rich plasma $\left(2 \times 10^{8}\right.$ platelets $\left./ \mathrm{ml}\right)$ caused by $2 \mu \mathrm{g} / \mathrm{ml}$ collagen, which was the threshold concentration to give maximal aggregation (Fig. 1). The extent of the inhibition depended on the concentration of monodansylcadaverine, and the median inhibitory concentration $\left(\mathrm{IC}_{50}\right)$ was about $120 \mu \mathrm{M}$. As shown in Fig. 2, $250 \mu \mathrm{M}$ monodansylcadaverine, which completely inhibited aggregation, inhibited the shape change induced by collagen. Secretion of serotonin and phosphorylation of the 47,000Da protein were also inhibited by monodansylcadaverine (Figs. 3 and 4).

Since monodansylcadaverine is a potent

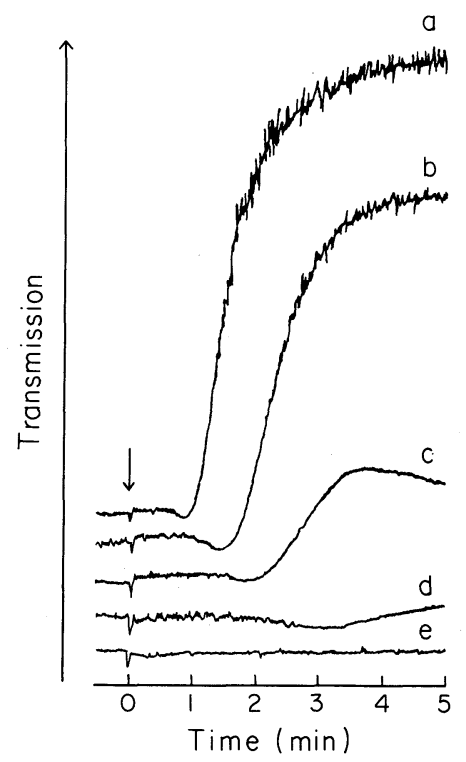

FIG. 1. Inhibition of Collagen-induced Platelet Aggregation by Monodansylcadaverine.

Platelet-rich plasma was stimulated by $2 \mu \mathrm{g} / \mathrm{ml}$ of collagen at $37^{\circ} \mathrm{C}$ in the absence $(a)$ or presence $(b, 100 \mu \mathrm{M} ; c, 150 \mu \mathrm{M}$; $d, 200 \mu \mathrm{M} ; e, 250 \mu \mathrm{M})$ of monodansylcadaverine. Collagen was added at the arrow. Aggregation was monitored as the increase of transmission of light. 

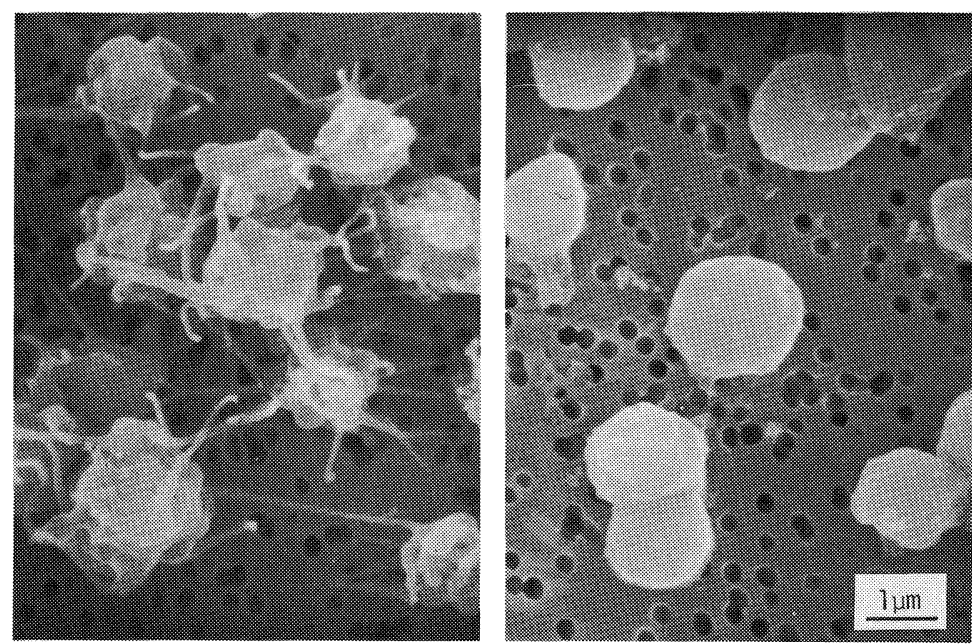

FIG. 2. Effects of Monodansylcadaverine on Platelet Shape Change.

Washed platelets were stimulated by $2 \mu \mathrm{g} / \mathrm{ml}$ of collagen at $37^{\circ} \mathrm{C}$ for $1 \mathrm{~min}$ in the absence (left) or presence (right) of $250 \mu \mathrm{M}$ monodansylcadaverine.

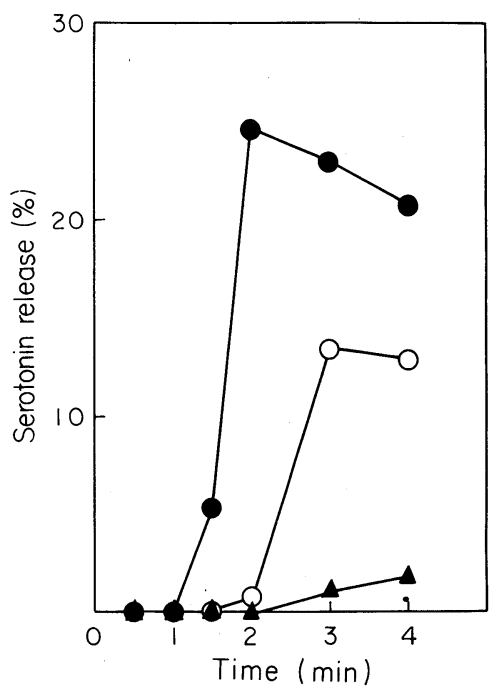

FIG. 3. Inhibition of $\left[{ }^{3} \mathrm{H}\right]$ Serotonin Release by Monodansylcadaverine.

Human platelets loaded with $\left[{ }^{3} \mathrm{H}\right]$ serotonin were stimulated by $2 \mu \mathrm{g} / \mathrm{ml}$ of collagen at $37^{\circ} \mathrm{C}$ for various periods of time in the absence $(\bigcirc)$ or presence $(\bigcirc, 50 \mu \mathrm{M} ; \boldsymbol{\Delta}, 250 \mu \mathrm{M})$ of monodansylcadaverine. Data are mean values of duplicate experiments.

inhibitor of transglutaminase, ${ }^{3,4)}$ these results apparently implicate the participation of the transglutaminase reaction in platelet aggregation. If this is the case, $\left[{ }^{3} \mathrm{H}\right]$ putrescine is expected to bind to platelet proteins during ag-

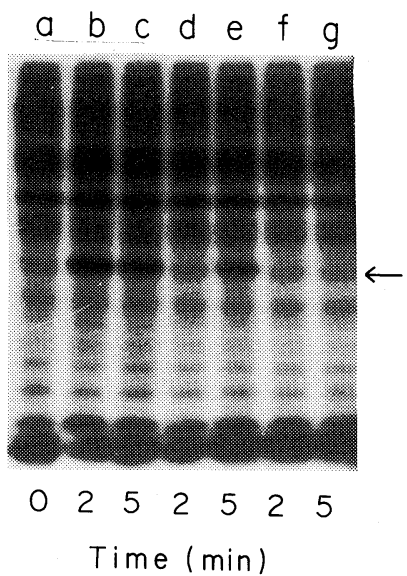

FIG. 4. Autoradiographs of ${ }^{32} \mathrm{P}$-Labeled Proteins from Human Platelets.

Platelets prelabeled with ${ }^{32} \mathrm{Pi}$ were stimulated by $2 \mu \mathrm{g} / \mathrm{ml}$ of collagen at $37^{\circ} \mathrm{C}$ for the indicated periods of time in the absence $(a \sim c)$ or presence ( $d$ and $e, 50 \mu \mathrm{M} ; f$ and $g, 250 \mu \mathrm{M}$ ) of monodansylcadaverine. Proteins from $5 \times 10^{6}$ platelets were resolved by electrophoresis on a $10 \%$ slab gel. The arrow indicates the position of the 47,000-Da protein.

gregation. Ten $\mu \mathrm{l}$ of $\left[{ }^{3} \mathrm{H}\right]$ putrescine $(0.5 \mu \mathrm{Ci} / \mu \mathrm{l})$ was added to $0.5 \mathrm{ml}$ of washed platelet suspension. After preincubation for $3 \mathrm{~min}$ at $37^{\circ} \mathrm{C}$, platelets were stimulated by $2 \mu \mathrm{g} / \mathrm{ml}$ of collagen for various intervals. The reaction was stopped by the addition of $1 \mathrm{ml}$ of trichloroacetic acid containing $2 \mathrm{~mm}$ putrescine. The 
precipitated proteins were washed with $5 \%$ trichloroacetic acid containing $2 \mathrm{~mm}$ putrescine and acetone. After solubilization with NCS solubilizer, radioactivity bound to proteins was counted in a liquid scintillation counter. However, binding of $\left[{ }^{3} \mathrm{H}\right]$ putrescine to platelet proteins was very low and independent on the stimulation of platelets by collagen (data not shown). It seems unlikely, therefore, that the transglutaminase reaction is involved in platelet aggregation.

\section{Effects of monodansylcadaverine on the metab-} olism of arachidonic acid in human platelets

As reported previously, collagen-induced aggregation of platelets depends on the formation of thromboxane $\mathrm{A}_{2}{ }^{1,2)} \mathrm{We}$ examined the effects of monodansylcadaverine on the metabolism of arachidonic acid. Monodansylcadaverine completely inhibited the formation of thromboxane $A_{2}$ (measured at thromboxane $\mathrm{B}_{2}$ ) at $250 \mu \mathrm{M}$ (Table I). The $\mathrm{IC}_{50}$ was about $120 \mu \mathrm{M}$, which was consistent with the value shown for aggregation. When platelets prelabeled with $\left[{ }^{14} \mathrm{C}\right]$ arachidonic acid were stimulated by $20 \mu \mathrm{g} / \mathrm{ml}$ of collagen, the radioactivities in thromboxane $\mathrm{B}_{2}$, hydroxyheptadecatrienoic acid, and hydroxyeicosatetraenoic acid increased (Table II). The increase in arachidonic acid metabolites was almost completely inhibited by $250 \mu \mathrm{M}$ monodansylcadaverine. If monodansylcadaverine inhibits cyclooxygenase and lipoxygenase, free arachidonic acid may be accumulated. Since the radioactivity in free arachidonic acid was too low to expose X-ray film regardless of the presence or absence of monodansylcadaverine, we suggested that monodansylcadaverine inhibited the release of arachidonic acid from phospholipids. Pincus et al. showed that monodansylcadaverine was incorporated into the plasma membranes of many cells and used it as a fluorescence probe for plasma membrane. ${ }^{19)}$ It is likely that monodansylcadaverine incorporated into platelet plasma membrane breaks a link between the stimulation and the release of arachidonic acid or directly inhibits enzymes related to the release of
TABLE I. Inhibition OF Thromboxane Synthesis BY MONODANSYlCADAVERINE

Platelet-rich plasma was preincubated at $37^{\circ} \mathrm{C}$ for 3 min with or without monodansylcadaverine, and then stimulated by $2 \mu \mathrm{g} / \mathrm{ml}$ collagen. The reaction was done at $37^{\circ} \mathrm{C}$ for $5 \mathrm{~min}$ and stopped by dilution with $12 \mathrm{~mm}$ Tris- $\mathrm{HCl}$ buffer, $\mathrm{pH} 7.4$, containing $0.14 \mathrm{M} \mathrm{NaCl}, 1.5 \mathrm{~mm}$ EDTA, and $0.14 \mathrm{~mm}$ indomethacin. Thromboxane $\mathrm{B}_{2}$ was assayed with radioimmunoassay kits. Data are mean values of duplicate experiments.

\begin{tabular}{cc}
\hline $\begin{array}{c}\text { Monodansylcadaverine } \\
(\mu \mathrm{M})\end{array}$ & $\begin{array}{c}\text { Thromboxane } \mathrm{B}_{2} \\
(\mathrm{ng} / \mathrm{ml})\end{array}$ \\
\hline 0 & 41.5 \\
100 & 22.6 \\
150 & 14.9 \\
200 & 5.9 \\
250 & 2.4 \\
\hline
\end{tabular}

Table II. EfFects of MonodansylCadaverine ON Arachidonic ACID Metabolism InduCED By Collagen

Washed platelets prelabeled with $\left[{ }^{14} \mathrm{C}\right]$ arachidonic acid were stimulated by $20 \mu \mathrm{g} / \mathrm{ml}$ of collagen at $37^{\circ} \mathrm{C}$ for $5 \mathrm{~min}$ in the absence or presence of $250 \mu \mathrm{M}$ monodansylcadaverine. Under these conditions, $250 \mu \mathrm{M}$ monodansylcadaverine inhibited about $95 \%$ of full aggregation as $10 \mu \mathrm{M}$ indomethacin did. Extracted lipids were separated on TLC (Materials AND Methods). Numerals are expressed as percentages of the total radioactivity recovered. DnsCad, monodansylcadaverine; $\mathrm{TXB}_{2}$, thromboxane $\mathrm{B}_{2} ;$ HHT, hydroxyheptadecatrienoic acid; HETE, hydroxyeicosatetraènoic acid; $20: 4$, arachidonic acid.

\begin{tabular}{lccc}
\hline & $\begin{array}{c}\text { - Collagen } \\
- \text { DnsCad }\end{array}$ & $\begin{array}{c}\text { +Collagen } \\
- \text { DnsCad }\end{array}$ & $\begin{array}{c}\text { + Collagen } \\
+ \text { DnsCad }\end{array}$ \\
\hline & & $(\%)$ & \\
$\mathrm{TXB}_{2}$ & $<0.1$ & 2.3 & 0.1 \\
HHT & $<0.1$ & 2.8 & 0.1 \\
HETE & $<0.1$ & 1.1 & 0.1 \\
$20: 4$ & $<0.1$ & $<0.1$ & $<0.1$ \\
\hline
\end{tabular}

arachidonic acid. Hence, we concluded that monodansylcadaverine inhibits cellular responses linked to platelet aggregation not by inhibiting the transglutaminase reaction but by altering lipid metabolism. Recently, Sundan et al. reported an inhibitory effect of monodansylcadaverine on the activation of phosphodiesterase by calmodulin. ${ }^{20)}$ It seems necessary to consider the effects of mono- 
dansylcadaverine on the $\mathrm{Ca}^{2+} /$ calmodulin system, since monodansylcadaverine structurally resembles a series of calmodulin antagonists, which have naphthalenesulfonamide backbones. ${ }^{21)}$

Acknowledgments. This research was supported by a Grant-in-Aid for Scientific Research from the Ministry of Education, Science and Culture of Japan and by the Special Coordination Funds for Promoting Science and Technology from the Science and Technology Agency of Japan.

\section{REFERENCES}

1) M. Kito, H. Narita, M. Ishinaga, H. J. Park and H. Takamura, J. Biochem., 97, 765 (1985).

2) H. Narita, H. J. Park, K. Tanaka, T. Matsuura and M. Kito, J. Biochem., 98, 1063 (1985).

3) P. J. A. Davies, D. R. Davies, A. Levitzki, F. R. Maxfield, M. C. Willingham and I. Pastan, Nature, 283, 162 (1980).

4) A. Levitzki, M. C. Willingham and I. Pastan, Proc. Natl. Acad. Sci. U.S.A., 77, 2706 (1980).

5) I. Cohen, T. A. Blankenberg, D. Borden, D. R. Kahn and A. Veis, Biochim. Biophys. Acta, 628, 365 (1980).

6) D. R. Kahn and I. Cohen, Biochim. Biophys. Acta, 668, 490 (1981).

7) I. Cohen, T. Glaser, A. Veis and J. Bruner-Lorand, Biochim. Biophys. Acta, 676, 137 (1981).
8) N. G. Ardlie and P. Han, Br. J. Haematol., 26, 331 (1974).

9) E. J. Harfenist, G. Raychaudhuri, M. A. Packham and J. F. Mustard, Blood, 60, 905 (1982).

10) J. M. Mato, D. Pencev, G. Vasatanthakumar, E. Schiffmann and I. Pastan, Proc. Natl. Acad. Sci. U.S.A., 80, 1929 (1983).

11) M. G. Gill, M. V. L. Campagne, P. Esbrit, F. Navarro and J. M. Mato, Biochim. Biophys. Acta, 794, 234 (1984).

12) D. S. Houston, J. M. Gerrard, J. McCrea, S. Glover and A. M. Butler, Biochim. Biophys. Acta, 734, 267 (1983).

13) C. S. Greenberg and M. A. Shuman, J. Biol. Chem., 259, 14721 (1984).

14) S. Rittenhouse-Simmons and D. Deykin, Biochim. Biophys. Acta, 426, 688 (1976).

15) M. Ishinaga, M. Kakuta, H. Narita and M. Kito, Agric. Biol. Chem., 47, 903 (1983).

16) E. Lapetina and P. Cuatrecasas, Biochim. Biophys. Acta, 573, 394 (1979).

17) J. L. Costa and D. L. Murphy, Nature, 255, 407 (1975).

18) U. K. Laemmli, Nature, 227, 680 (1970).

19) J. H. Pincus, S. I. Chung, N. H. Chace and M. Gross, Arch. Biochem. Biophys., 169, 724 (1975).

20) A. Sundan, K. Sandvig and S. Olsnes, Biochem. Biophys. Res. Commun., 117, 562 (1983).

21) H. Hidaka, Y. Sasaki, T. Tanaka, T. Endo, S. Ohno, Y. Fujii and T. Nagata, Proc. Natl. Acad. Sci. U.S.A., 78, 4354 (1981). 